\title{
Modelling and Performance Evaluation of Ground based Monostatic Radar Surveillance System
}

\author{
Bassey A. George \\ Dept. of Electrical/Electronic and \\ Computer Engineering, Univ. of \\ Uyo, Nigeria
}

\author{
Akaninyene B. Obot \\ Dept. of Electrical/Electronic and \\ Computer Engineering, Univ. of \\ Uyo, Nigeria
}

\author{
Kufre M. Udofia \\ Dept. of Electrical/Electronic and \\ Computer Engineering, Univ. of \\ Uyo, Nigeria
}

\begin{abstract}
The modelling and performance evaluation of ground based monostatic radar surveillance system presented in this paper is analysed in terms of system performance results, input data of the radar system and its operating mode. Radar equations are derived to obtain the minimum detection signal $\left(\mathrm{P}_{\min }\right)$, system loss $\left(\mathrm{L}_{\mathrm{sys}}\right)$, minimum signal-to-noise ratio $(\mathrm{SNR})_{\min }$ and maximum detection range equation $\left(\mathrm{R}_{\max }\right)$ respectively. Radar parameters such as transmit peak power $\left(\mathrm{P}_{t}\right)$, antenna gain (G), radar cross section (RCS), bandwidth (B), and other parameters are analysed in the radar equations. Radar system losses $\left(\mathrm{L}_{\mathrm{sys}}\right)$ are accounted into the modified radar equations and calculated to be $21.1 \mathrm{~dB}$. The modified radar equations with $P_{t}=15 \mathrm{~kW}$, and $R_{\max }=500 \mathrm{~km}$, also gives a significantly lower value of $\mathrm{SNR}=27.0 \mathrm{~dB}$. Analysing the radar performance, MATLAB simulation program is used to evaluate the radar performance equations with different parameter values. Target detection radar signal is a difficult problem when the SNR is low, thereby causing the constant false alarm rate (CFAR) processor to adjust threshold. Simulation results are presented respectively.
\end{abstract}

\section{Keywords}

Radar System, System loss, Range and Signal to noise ratio.

\section{INTRODUCTION}

The concept and invention of radar, was discovered in the beginning of the $20^{\text {th }}$ century simultaneously in many countries such as Japan, Germany, United States, France, Italy, Netherlands and United Kingdom in the early 1920s [1]. Originally, radar was developed to meet the needs of the military services, and also the critical applications for national defence purposes [2]. Radar refers to radio detection and ranging. It is an electronic equipment that detects the presence and location of reflecting objects (targets) such as aircraft, ships, spacecraft, vehicles, people, iceberg and the natural environment by using reflected electromagnetic energy [3].

The basic radar concept is that radio frequency (RF) energy is generated by transmitting a particular type of waveform, radiated by the transmitting antenna, reflected by the target, collected by the receiving antenna and detects the nature of the returned echo signal in the radar receiver [4]. In addition, radar controls and guides, weapons, allows one class of target to be distinguished from another, aids in the navigation of aircraft and ships, and also assist in reconnaissance and damage assessment [2].

Readers can be classified as ground based, airborne, space borne or ship based and weather radar systems. They can also be classified into numerous categories based on the specific radar characteristics such as the frequency band, antenna types and waveform utilized [5,6,7]. Where a radar is based or located, will determine to a large degree the spatial coverage of the radar waves and the kind of targets it may observe or track [4]. The major categories where radar are based, are terrestrial, airborne, and space-based. In order to predict radar performance, detectable signal must be modified to include external factors. External factors affecting radar performance include: target characteristics; external noise that might enter via the antenna; unwanted clutter echoes from land, sea, birds, or rain; interference from other electromagnetic radiators; and propagation effects due to the earth's surface and atmosphere. The parametric factors affecting radar maximum equation range include noise factor, system losses, pulse integration, high pulse repetition frequencies and effect of earth reflection, atmospheric attenuation, refraction, diffraction, interference, clutter target size, receiver noise and free space loss $[1,6]$. The major tool and the ability of a radar to detect the presence of a target is expressed in terms of the radar range equation with respect to its parameters.

\section{REVIEW OF RELATED WORKS}

Radar equation is derived from the authors [8] to obtain the equations for the minimum detection range $\left(\mathrm{R}_{\min }\right)$ and maximum signal to noise ratio (SNR) $\max$ equations respectively. From the derived equations, high and low pulse repetition frequency accounted for and allocated in the radar equation. Analysing the radar performance using several choices parameters like transmit power (MW), radar cross section area $\left(\mathrm{m}^{2}\right)$, antenna gain $(\mathrm{dB})$, coherent pulses $(\mathrm{sec})$, duty cycle and other parameters were considered. The authors assumed and allocated values for each respective parameter with a SNR of $<=80 \mathrm{~dB}$, power of $65 \mathrm{MW}$, RCS $10 \mathrm{~m}^{2}$ and minimum range of $50 \mathrm{~km}$. Although system losses were not included, MATLAB simulation tool was used for analysing the radar performance for range, gain, SNR and power respectively.

Authors [9] derived radar equation to obtain equations for the $\mathrm{R}_{\min }$ and maximum SNR respectively. Some assumed radar parameter values were allocated for $\mathrm{P}_{\mathrm{t}}$, radar cross section RCS and antenna gain $(\mathrm{G})$ and other relevant parameters. The authors analysed the derived radar equations without accounting for any other parameters including system losses, and used MATLAB to evaluate the radar performance with respect to the parameters.

Both authors had it that the peak power has little effect on improving the detection range or SNR when compared with other radar parameters such as RCS and antenna gain, because the transmitted and received signal power is proportional to the fourth power of the range while in communication systems is proportional to square power of the range, that 
means the radar's received energy drops with the fourth power of the distance.

\section{METHODOLOGY}

The major tool and the ability of radar to detect the presence of a target are expressed in terms of the radar range equation. To evaluate the performance of a radar system, radar equation needs to be derived rather than just quoted because of the insight it gives into the way radar works. These equations are derived to include some main parameters such as transmitting and receiving powers, antenna gain, radar cross section, radar range and frequency from the ground based civilian monostatic aircraft radar. In this paper, Lagos, radar system parameter is considered.

\subsection{Radar Performance Parameters}

The radar parameters can be used to evaluate radar performance system. These parameters include: frequency (in hertz), transmit and receive powers (in watts), signal to noise ratio (in decibels), radar cross section (metres square), range (in nautical miles or metres), temperature (in Kelvin), bandwidth (in hertz), pulse width (in seconds) and antenna gain (in decibels).

The radar equation gives the range in terms of the characteristics of the transmitter, receiver, antenna, target and environments [9]. It is the basic tool for understanding radar operation. The radar has several different forms and will be derived accordingly from first principle. The radar aiming distance $(\mathrm{R})$ is determined from the running time of the high frequency transmitted signal $(\mathrm{t})$ and the propagation velocity $\left(C_{o}\right)$ given as Equation $1[3,4,5]$.

$R=\frac{C_{o} \cdot t_{\text {delay }}}{2}$

Where $\mathrm{R}$ is the range, distance or antenna - aim $(\mathrm{km})$, $\mathrm{t}_{\text {delay }}$ is the two way path between the antenna and the target and $\mathrm{C}_{\mathrm{o}}$ is the propagation velocity equals $3.0 \times 10^{8}(\mathrm{~m} / \mathrm{s})$.

\subsection{Derivation of Minimum Detectable Range and Maximum Range Equation}

The detection range of a radar system is primarily a function of three parameters; transmitter power, antenna gain and receiver sensitivity [10]. Since the same antenna is used for transmitting and receiving, then we have that the gain of an antenna is also related to the capture area given by Equation 2 $[4,11]$.

$$
G_{r}=\frac{4 \pi A_{e}}{\lambda^{2}}
$$

$A_{e}$ is the effective antenna area as given in Equation 3

$A_{e}=\frac{G_{r} \lambda^{2}}{4 \pi}$

where $\lambda$ is the wave length given as $\lambda=\frac{C}{f}$

The power density (in watt per square meter) at the distance $\mathrm{R}$ away from the target location from an isotropic antenna is given by

$$
P_{d}=\frac{P_{t}}{4 \pi R^{2}} \quad\left[\mathrm{Wm}^{2}\right]
$$

For radar using a directive antenna with the gain of $G_{t}$, then the reflected power density of the target is given by Equation
$P_{d}=\frac{P_{t} G_{t}}{4 \pi R^{2}}$

The target reflects part of its energy, the measure of the amount of reflected incident power intercepted by the target and re-radiated back in the direction of the radar is denoted by the cross section $(\sigma)[11]$.

$\sigma=\frac{\text { power backscattered to radar, } P_{r}}{\text { power density at target, } P_{d}}\left(\mathrm{~m}^{2}\right)$

The reflected power from the target is given by Equation 7 .

$P_{d}=\frac{P_{t} G_{t} \sigma}{4 \pi R^{2}}$

The power density (in watts per square meters) of echo signal back to the to the radar antenna location becomes.

$P_{d}=\frac{P_{t} G_{t} \sigma}{4 \pi R^{2} 4 \pi R^{2}}$

The effective capture area of the receiving antenna is $A_{e}$, then power received becomes

$P_{r}=\frac{P_{t} G_{t} \sigma A_{e}}{4 \pi R^{2} 4 \pi R^{2}}$

Putting Equation 3 into Equation 9 yields.

$P_{r}=\frac{P_{t} G_{t} G_{r} \sigma \lambda^{2}}{(4 \pi)^{3} R^{4}}$

For monostatic radar the transmitting and receiving gains are equal $\left(G_{t}=G_{r}\right)$, which implies $G^{2}$. Hence, Equation 10 becomes

$P_{r}=\frac{P_{t} G^{2} \sigma \lambda^{2}}{(4 \pi)^{3} R^{4}}$

Equation 11 is the minimum detectable signal radar in watts.

Figure 1 shows the radar detection performance parameters that gave rise to the Equation 11

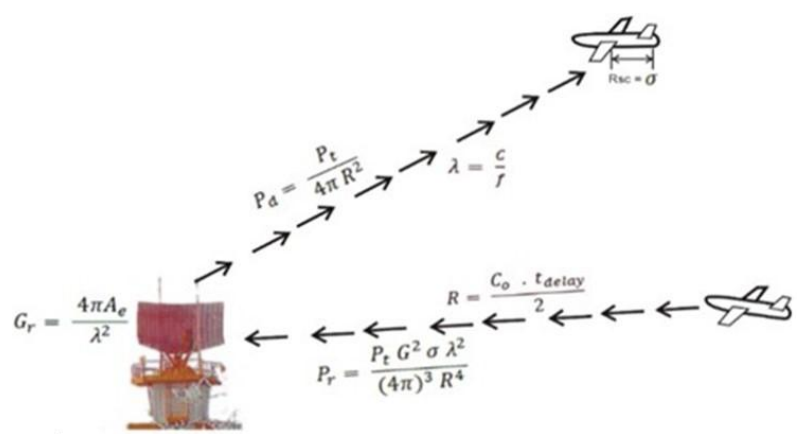

Fig 1: Radar system detection

$\mathrm{R}^{4}$ is the distance of aim determined from the running time of the antenna high frequency transmitted signal and the propagation velocity $\mathrm{C}_{\mathrm{o}}$ from Equation 1 .

The minimum detectable signals or smallest received power that can be detected by radar is given as $\mathrm{P}_{\min }$. If $\mathrm{P}_{\mathrm{r}}=\mathrm{P}_{\min }$, then the $R_{\max }$ which is the maximum distance which the target can be detected. Thus, minimum power to detect at $R_{\max }$ is given by the Equation 12 .

$R_{\max }=\sqrt[4]{\left[\frac{P_{t} G^{2} \lambda^{2} \sigma}{(4 \pi)^{3} P_{\min }}\right]}$

Equation 12 is another form of the radar equation.. The maximum radar range is the distance beyond which the required signal is too small for the system operation $[3,5,12]$. 
The noise figure of a receiver is given by Equation 13. Where the receiver noise power is given as Equation 14

$F=\frac{(S N R)_{i}}{(S N R)_{o}}=\frac{S_{i} / N_{i}}{S_{o} / N_{o}}$

$N_{i}=k T_{s} B$

When $S_{i}=P_{\min }$ and $\left(\frac{s_{i}}{s_{o}}\right)=\left(\frac{s_{i}}{s_{o}}\right)_{\text {min }}$, then minimum detectable signal, $\mathrm{P}_{\min }$ is that value of corresponding to the minimum ratio of $(\mathrm{S} / \mathrm{N})_{\min }$ necessary for detection, then the minimum receive signal is thus given by Equation 20 [11,13].

$P_{\text {min }}=k T_{S} B F\left(\frac{S}{N}\right)_{\text {min }}$

Substituting this Equation 15 into the radar Equation 12, gives Equation 16;

$R=R_{\max }=\left[\frac{P_{t} G^{2} \lambda^{2} \sigma}{(4 \pi)^{3} k B T_{S} F\left(\frac{S}{N}\right)_{\min }}\right]^{\frac{1}{4}}$

Where $\mathrm{k}$ is Boltzmann's constant $\left(1.38 \times 10^{-23} \mathrm{~J} / \mathrm{K}\right)$, $\mathrm{T}$ is absolute temperature in Kelvin, B is the bandwidth in hertz, $\mathrm{F}$ is the noise figure (unit less, linear form), and $(\mathrm{S} / \mathrm{N})$ is a minimum output signal to noise ratio in ratio.

The minimum signal to noise figure is obtained from Equation 16 to be given by Equation 17 as;

$\left(\frac{S}{N}\right)_{\min }=\left[\frac{P_{t} G^{2} \lambda^{2} \sigma}{(4 \pi)^{3} R^{4} k B T_{S} F}\right]$

\subsection{Radar System Losses}

Several losses of various types must be accounted for in real radar. Several radar systems experience most of these losses common to tracking system plus other losses common to only search system [14]. Losses which cannot be calculated include those due to field degradation and operator motivation [15]. These are values that are calculated to compensate for attenuation by precipitation, atmospheric gases, and receiver detection limitations.

The following losses are encountered during the radar system performance [16]: Atmospheric loss $\left(\mathrm{L}_{\mathrm{a}}\right)$, beam shaped loss $\left(\mathrm{L}_{\text {ant }}\right)$, beam width factor $\left(\mathrm{L}_{\mathrm{B}}\right)$, filter matching loss $\left(\mathrm{L}_{\mathrm{m}}\right)$, antenna efficiency loss $\left(\mathrm{L}_{\mathrm{ef}}\right)$, fluctuation loss $\left(\mathrm{L}_{\mathrm{f}}\right)$, receive line loss $\left(\mathrm{L}_{\mathrm{r}}\right)$, transmit line power $\left(\mathrm{L}_{\mathrm{t}}\right)$, scanning loss $\left(\mathrm{L}_{\mathrm{s}}\right)$, Propagation loss $\left(\mathrm{L}_{\mathrm{p}}\right)$, Miscellaneous signal process loss $\left(\mathrm{L}_{\mathrm{sp}}\right)$. The total system losses are given in Equation 18

$L_{s y s}=L_{a}+L_{a n t}+L_{B}+L_{a}+L_{s}+L_{f}+L_{t}+L_{r}+L_{m}$

$$
+L_{s p}+L_{p}+L_{e f}
$$

The total system losses are obtained by adding the respective system losses as shown in Table 1

Table 1: Parameters system losses

\begin{tabular}{lcc}
\hline Components & Symbol & Loss \\
\hline Atmospheric loss & $\mathrm{L}_{\mathrm{a}}$ & $1.2 \mathrm{~dB}$ \\
Beam shaped loss & $\mathrm{L}_{\mathrm{ant}}$ & $1.3 \mathrm{~dB}$ \\
Beam width factor & $\mathrm{L}_{\mathrm{B}}$ & $1.2 \mathrm{~dB}$ \\
Filter matching loss & $\mathrm{L}_{\mathrm{m}}$ & $0.8 \mathrm{~dB}$ \\
Antenna efficiency loss & $\mathrm{L}_{\mathrm{ef}}$ & $1.2 \mathrm{~dB}$ \\
Fluctuation loss & $\mathrm{L}_{\mathrm{f}}$ & $6.4 \mathrm{~dB}$ \\
Receive line loss & $\mathrm{L}_{\mathrm{r}}$ & $1.0 \mathrm{~dB}$ \\
Transmit line power & $\mathrm{L}_{\mathrm{t}}$ & $1.0 \mathrm{~dB}$ \\
Scanning loss & $\mathrm{L}_{\mathrm{s}}$ & $2.0 \mathrm{~dB}$ \\
Propagation loss & $\mathrm{L}_{\mathrm{p}}$ & $2.0 \mathrm{~dB}$ \\
Miscellaneous signal process $\mathrm{L}_{\mathrm{sp}}$ & $3.0 \mathrm{~dB}$ \\
\hline Total losses & $\mathrm{L}_{\mathrm{sys}}$ & $21.1 \mathrm{~dB}$ \\
\hline
\end{tabular}

\subsection{Modified Radar Equation}

The Equations 19 and 20 show the modified radar model equation, including system loss factor $\left(\mathrm{L}_{\mathrm{sys}}\right)$.

$$
\begin{aligned}
& R_{\text {max }}=\left[\frac{P_{t} G^{2} \lambda^{2} \sigma}{(4 \pi)^{3} k B T_{s} F\left(\frac{S}{N}\right)_{\text {min }} L_{s y s}}\right]^{\frac{1}{4}} \\
& \left(\frac{S}{N}\right)_{\text {min }}=\left[\frac{P_{t} G^{2} \lambda^{2} \sigma}{(4 \pi)^{3} R^{4} k B T_{s} F L_{s y s}}\right]
\end{aligned}
$$

Where $T_{\mathrm{s}}$ is the system temperature $(\mathrm{K}), \mathrm{S}_{\mathrm{o}} / \mathrm{N}_{\mathrm{o}}$ is minimum receiver output signal-to-noise ratio (unit less, linear form), $\lambda$ is wavelength $(\mathrm{m}), \mathrm{P}_{\mathrm{t}}$ is transmit peak power $(\mathrm{W}), \mathrm{G}$ is antenna gain (unit less), $\sigma$ is radar cross section $\left(\mathrm{m}^{2}\right), \mathrm{L}_{\mathrm{sys}}$ is system loss in ratio (unit less, linear form) and $\mathrm{R}$ is the radar range (m)

Table 2 shows some of the allocated and calculated parameter values which is substituted into the modified radar Equations 19 and 20 used by MATLAB program [17] to obtain the respective radar analysis.

Table 2: AN2000STAR Primary radar performance parameters

\begin{tabular}{lll}
\hline Symbol & System Parameters & Values \\
\hline $\mathrm{S}$ & Frequency & $2.8 \mathrm{GHz}$ \\
$\tau$ & Pulse width & $7.5 \times 10^{-6} \mathrm{~s}$ \\
$\sigma$ & Cross sectional area & $40 \mathrm{~m}^{2}, 60 \mathrm{~m}^{2}, 90 \mathrm{~m}^{2}, 100 \mathrm{~m}^{2}$ \\
$\mathrm{P}_{\mathrm{t}}$ & Peak power & $15 \mathrm{~kW}, 10 \mathrm{~kW}, 9 \mathrm{~kW}, 5 \mathrm{~kW}$ \\
$\mathrm{~F}$ & System noise stability figure & $15 \mathrm{~dB}$ \\
$\mathrm{~T}_{\mathrm{i}}$ & Beam time rate & $3.3 \mathrm{~ms}$ \\
$\mathrm{R}$ & Radar distance & $500 \mathrm{~km}$ \\
$\left(\mathrm{SNR}_{\mathrm{o}}\right)_{\min }$ & Signal to noise ratio & $48.1 \mathrm{~dB}$ \\
$\left(\mathrm{SNR}_{\mathrm{o}}\right)_{\min }+$ loss & Signal to noise ratio & $27.0 \mathrm{~dB}$
\end{tabular}




\begin{tabular}{lll}
$\mathrm{L}_{\mathrm{sys}}$ & System losses & $21.1 \mathrm{~dB}$ \\
$\mathrm{G}$ & Antenna gain & $30 \mathrm{~dB}, 32 \mathrm{~dB}, 33 \mathrm{~dB}, 35 \mathrm{~dB}$ \\
$\mathrm{~B}$ & Bandwidth & $1.333 \times 10^{-6} \mathrm{~Hz}$ \\
$\lambda$ & Wavelength & $0.1111 \mathrm{~m}$ \\
$\mathrm{PRT}$ & Pulse repetition time & $1.0 \times 10^{-04} \mu \mathrm{sec}$ \\
$\mathrm{A}_{\mathrm{e}}$ & Antenna effective aperture & $1.95 \times 10^{26} \mathrm{~m}^{2}$ \\
$\mathrm{C}$ & Speed of light & $3.0 \times 10^{08} \mathrm{~m} / \mathrm{s}$ \\
$\mathrm{T}$ & Temperature & $290 \mathrm{~K}$ \\
$\mathrm{~K}$ & Boltzmann's constant & $1.38 \times 10^{-23} \mathrm{~J} / \mathrm{K}$ \\
\hline & Probability of detection $(\mathrm{Pd})$ & $>99 \%$ \\
& False target report ratio & $<0.1 \%$ \\
& Multiple target reports & $<1$ per scan \\
& Azimuth accuracy & $<0.07^{\circ}$
\end{tabular}

\section{RESULTS AND DISCUSION}

The results of the simulated Equations 19 and 20 are as shown in the following Figures 2 to 5 .

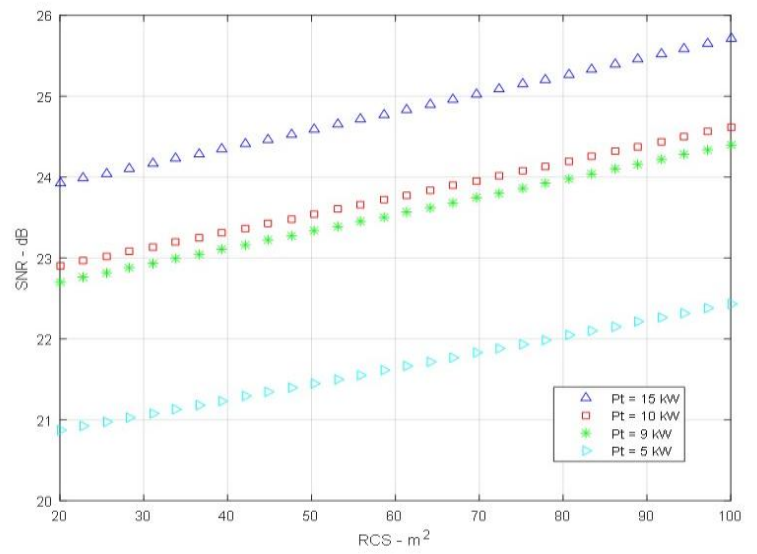

Fig 2: SNR versus detection range for different choices of transmit power

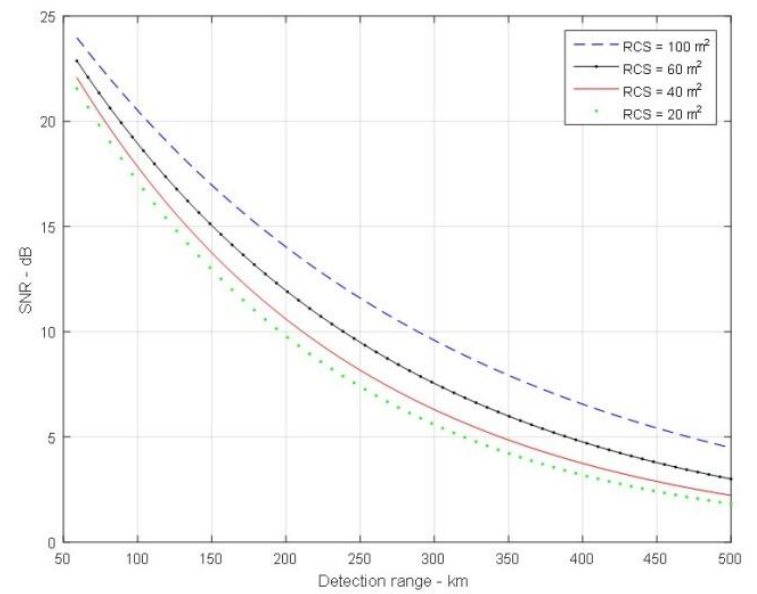

Fig 3: SNR versus detection range for several choices RCS

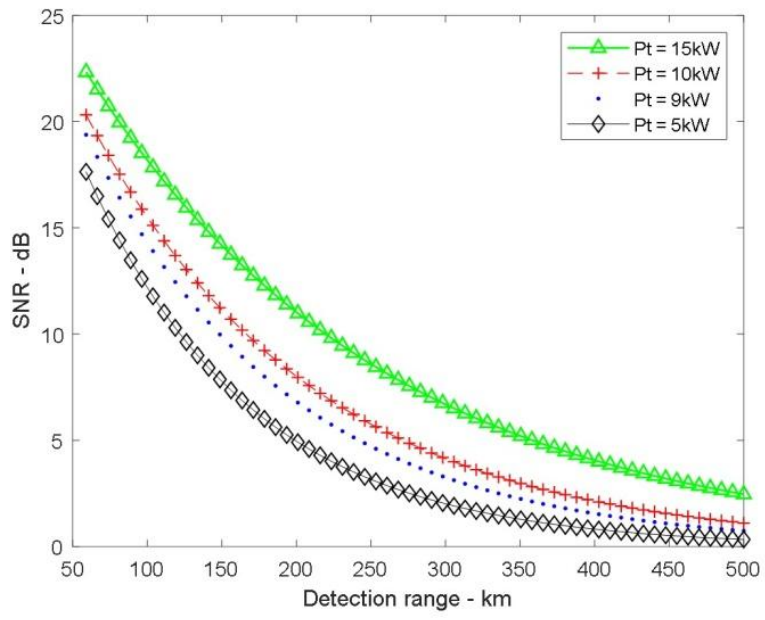

Fig 4: SNR versus RCS for several choices of transmit power

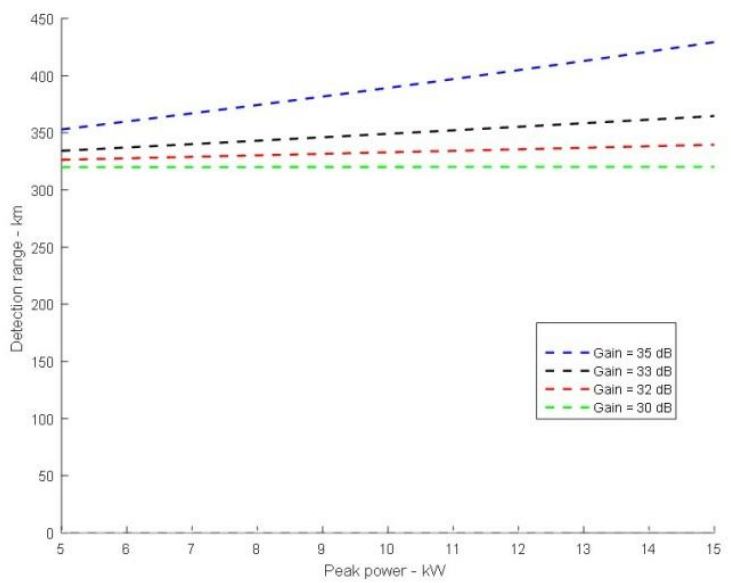

Fig 5: Detection range versus peak power with various choices of gain

Figure 2 shows the SNR plotted against detection range with different peak power. This gives an exponential increase in 
the detection range with increasing SNR while SNR decreases linearly with increasing detection range of different peak power values. When system loss is considered in the existing radar equation, SNR is reduced to a certain value in which, if the loss is excessive may affect the system performance. SNR is mostly a factor that affects radar performance if not properly determine. Thus affecting the probability of good detection.

Figure 3 shows an exponential increase in detection range for different RCS. With different RCS, SNR decreases exponentially with increasing detection range when plotted against detection range. In radar equation, SNR and range is a function of gain, RCS, wavelength and peak power, target (aircraft) with RCS $\left(20 \mathrm{~m}^{2}\right)$ and minimum SNR of $15 \mathrm{~dB}$ value may still be detected with respect to the antenna gain, frequency and range.

Figure 4 shows a plot of SNR (dB) against RCS $\left(\mathrm{m}^{2}\right)$, using different peak power to determine the performance in terms of SNR. The RCS decreases linearly with a power increase as SNR increases. Considering $15 \mathrm{~kW}$ power as the default power for LMMIA, it shows that for a transmit power to reflect clear and strong reflected or received energy from a target under heavy atmospheric attenuation like snow or rain, the transmit power needs to be high even up to megawatt. Although power in $\mathrm{kW}$ still gives a strong effect on radar signal no matter the target RCS.

Figure 5 shows the detection range plotted against peak power with different values of gain. At the default gain of $35 \mathrm{~dB}$, the is a clear and significant space between others, giving a better performance at a power of $15 \mathrm{~kW}$ as compared to other gain of $30 \mathrm{~dB}$ to $33 \mathrm{~dB}$. But to have a significant minimum detection range the power may need to be in megawatt. Power in milliwatt is not required in radar signal transmission because low power may give low signal. Therefore, for a gain of $30 \mathrm{~dB}$ to $33 \mathrm{~dB}$, detection power needs to be in kilowatt or megawatt.

\section{CONCLUSION}

MATLAB program was developed to determine detection range and SNR for the different parameters as a function of the radar range equation to analyse radar performance. The system loss $\mathrm{L}_{\mathrm{sys}}=21.1 \mathrm{~dB}$ has a significantly high value which may probably have an effect in slowing down the probability for better detection. Equation 20 has a significant effect on the radar performance with $\mathrm{SNR}_{\max }=27.0 \mathrm{~dB}$. This SNR value is considered low. Hence, with the SNR low, target detection radar signals become a difficult problem. Constant false alarm rate processors are typically used in radar applications. CFAR processors are suitable for targets with large enough SNR. Consequently, for such targets the CFAR processor can set the detection threshold higher, and will miss low-SNR targets. Finally, there is the need to eliminate excessive losses from the radar system.

\section{REFERENCES}

[1] Skolnik, M. I., Radar Hand Book. 3rd edition, ARTECH HOUSE, 2008. McGraw-Hill Inc, New Delhi

[2] Pike, J., Types of Radar.
[3] http://www.globalsecurity.org/military/system/aircraft/ra dar-type.htm.Modified 07-07-2011.

[4] Skolnik, M. I., Introduction to Radar System. 3rd Edition. Tata McGraw-Hill Publishing Company Limited, 2004. 7 West Patel Nagar, New Delhi.

[5] Curry, R. G., Radar System Performance Modeling. 2nd Edition ARTECH HOUSE, INC, 2005, 658 Canton Street, Norwood, MA.

[6] Mahafza, B. I., Radar system Analysis and Design using MATLAB. 2013. CRC Press. Taylor and Francis Group.

[7] Noth, K. R. and Luke, D. W., Modelling and Simulation of Ground Based Radar Surveillance Solution for Unmanned Aircraft system Sense and Avoid. 2011. American Institute of Aeronautics and astronautics Inc. MITRE cooperation, Burlington, Bedford, MA, August 2011.

[8] NAMA (Nigerian Airspace Management Agency). Official training material 1 and 2 on Thales AN2000 STAR primary and RMS970 secondary radar antenna. 2018. Port Harcourt International Air Port, River State. www.@nama.gov.ng

[9] Sulaiman, H. M., Sadoon, A. I and Badal, H. E., Radar Theoretical Study: Minimum Detection Range and Maximum Signal to Noise Ratio (SNR) Equation by Using MATLAB Simulation Program. 2013. Science publishing group

[10] Shrivas, A. K and Mudalisar A. Performance Evaluation of Radar systems.. International Journal of Innovative Research In. Computer and Communication Engr. 2015. 3(7) Chattisgarh, India.

[11] Wolff, C. B. W., Radar Basics. 'Antenna' Book 3. https://www.radartutorial.eu/internetsite/01.basic/rb13.en .html (GNU FREE DOCUMENTATION)

[12] Chang, k., RF and Microwave Wireless System. Wileyinterscience publication, John wiley and sons Inc., 2000. New York. 196p, 217p

[13] Nathanson, F. E., Reilly, P. J and Cohen, M. N., Radar Design Principle. 1999. SciTech publishing, Inc, 89 dean road, New Jersey, USA. 222p

[14] Barton, D. K., Modern Radar System Analysis. 3rd edition. Artech House, 2000. Norwood MA

[15] Meyer, D. P and Mayer, H. A., Radar Target Detection. Academic press, subcidiary of harcourt brace Jovanvich publication, 1973. New York, USA. 14p.

[16] Bhupender, R., Prediction of Range Performance 2018. https://www.slideshare.net

[17] Wolff, C. B. W., Radar Basics. 'Operation' Book 2. https://www.radartutorial.eu/internetsite/01.basic/rb13.en .html (GNU FREE DOCUMENTATION)

[18] Matrix Laboratory/Simulink Simulation Tool (MATLAB) 2014 Version. Technical Computer Language with installation license 0.78564 a version 2014. 